\title{
Sentiment analysis of social commerce: A harbinger of online reputation management
}

Sunday Adewale Olaleye*

Oulu Business School

Erkki Koiso-Kanttilan katu

90570, Oulu, Finland.

Email: sunday.olaleye@oulu.fi

*Corresponding author

Ismaila Temitayo Sanusi

University of Eastern Finland

Yliopistokatu 2, 80100 Joensuu

PL 111, 80101 Joensuu, Finland.

Email: ismails@uef.fi

Jari Salo

University of Helsinki

PL 27 (Latokartanonkaari 5)

00014, Helsinki, Finland.

Email: jari.salo@helsinki.fi

\begin{abstract}
Social media, a combination of socialization and media is diffusing and impacting different business sectors, and non-governmental organization globally. Social media coalesce traditional print and electronic media, and it is advancing the marketing mix most especially the communication marketing mix. Online reputation management is an extension of public relations, a long-time practice of organization image laundering through print and online media. This study argues that sentiment analysis of product or service evaluation is an antecedent of online reputation management. This study applies the hybrid technique to sort out social commerce customers' reviews, appraise the quality of the extracted data and identify the opinion that transpired between online retailing merchants and online customers. The framework proposed in this study will serve as a foundation and precedent for an effective online reputation management and stands to improve customer service. This study offers some managerial implications and indicates future research.
\end{abstract}

Keywords: Social Commerce, Facebook, Social Media, Sentiment, Mobile Commerce, Review, Appraisal, Online Reputation Management.

\section{Reference}

Biographical notes: Sunday Adewale Olaleye had a Master of Science in Information Systems from the Abo Akademi University, Turku, Finland, Master of Business Administration (MBA), Lapland University of Applied Sciences, Tornio, Finland, NMS iICT Certificate, Innovation and Entrepreneurship, Nordic Master School of Innovative ICT, Turku Centre for Computer Science (TUCS), Turku, Finland and Certificate of Leadership and Management in Health from the University of Washington, USA. Currently doing his doctoral studies at the Department of Marketing, Management and International Business, Oulu Business School, Finland. He has presented papers at conferences and published in academic journals. His research interests are Emerging Mobile Technologies, Tablet Commerce, Mobile Commerce, Social Commerce and Mobile Apps. 
Ismaila Temitayo Sanusi is a Ph.D. student at the Philosophical Faculty, University of Eastern Finland. His research interest is in Mobile Technologies, ICT in Education, Entrepreneurship, and TVET. He has presented papers at conferences and published in academic journals.

Jari Salo is a full professor at the Department of Economics and Management, University of Helsinki. $\mathrm{He}$ is also an adjunct professor of marketing at the School of Business at the Aalto University. Salo has more than 100 publications on digital and industrial marketing published in international academic journals. He has been organizing many conferences and is an active member in several editorial boards.

This paper is a revised and expanded version of a paper entitled 'The appraisal of Facebook online community: An exposition of mobile commerce in social media reviews' presented at the 30th Bled eConference on Digital Transformation, Bled, Slovenia, 18-21 June, 2017.

\section{Introduction}

Social media, a combination of socialization and media is diffusing and impacting different business sectors, and non-governmental organization globally. Social media coalesce traditional print and electronic media, and it is a perpetual threat to the traditional media. Social media is advancing the marketing mix most especially the communication marketing mix and it is an investment that has a viable return on investment (ROI) if it is managed professionally. Electronic and mobile commerce merchants are benefiting from the disruption of social media and it is has become a quick point of contact with the customers. Social media is viable tool for pre-sales, sales and post-sales services. It is a tracking and conversion tool that cannot be under-estimated in online business. Social media is good for networking, collaboration, socialization, online review and a strategic platform for online reputation management data. The margin between the services rendered to a customer and satisfaction or dissatisfaction of the impact of the services mastermind sentiment which could be positive, negative or neutral. The positive product or service feedback is a credit to the seller or the vendor of the ecommerce or mobile commerce platform, negative feedback may be detriment to the business and hampered return purchase and even affect the third parties while neutral is not beneficial to the both parties. This study argues that sentiment analysis of product or service evaluation is an antecedent of online reputation management.

Facebook is one of the aspect of social media that is soaring. For instance, in Nigeria Facebook users has increased to 16 million (Internet World Stats, 2017) and this is a great advantage for the online retailers to utilize for customer's engagement, conversion and retention. Facebook is a low-cost marketing strategy and it is helping the start-ups business to be visible online and to create awareness about their products and services. Social media most especially Facebook is disintermediating the agency relationship between the seller and the buyer and paving the way for the customer to have direct business relationship with the producer. Online reputation management is an extension of public relations, a long-time practice of organization image laundering through print and online media. The emergence of online reputation management has given birth to a lot of start-ups as a public relation professionals, experts and consultants (Hoffman, 2008). In Lagos, Nigeria presently, there are less than 30 online reputation management services providers. Though this is small in comparison with the global online reputation services providers, but it is an indication that Nigeria also is growing in online reputation management services. Social media particularly Facebook is playing a dual role of a friend and a foe in business transaction. A friend in the sense that it is helping the business owner to generate traffic and to promote their business for the purpose of sales and profit 
making but on the other hand a foe because anybody can write any negative comments, review concerning a particular company, product or service without a security review.

The online reputation service providers are trying to fill the gap of censoring, but the services are not proactive but reactive and the gap of being proactive can only be fill by the business owner, manufacturers themselves. Portmann, Meier, Cudré-Mauroux, and Pedrycz, $(2015,90)$ underscored the importance of a reputation and described online reputation as "the publicly kept social evaluation of an entity based on the entities previous behavior, what was posted by the entity, and what third parties share about the entity on the Internet." But Dijkmans, Kerkhof, and Beukeboom, $(2015,58)$ depicts corporation reputation as "a valuable intangible asset for companies" that is difficult to manage. It is beneficial and strategic for an online merchant to be reputable because it is a path of building trustworthy online platform for online shopping. Online reputation management is sequential and it "is the task of monitoring, addressing, or rectifying undesirable or negative mentions on the Web" (Portmann, et al., 2015, 93). This study expands this postulation and define online reputation management as a professional tactics to detect detrimental online comments, monitoring and counter the negativity on the Web. No matter how simple the online reputation management portray, Hoffman, (2008) said it requires a robust algorithms and complex technique to launder the dented image and recommends four simple steps to online reputation management. Randomly search the company name through Google search engine, use free online tools to know what the public are saying about your company, product and service, set up Google alert to know when your company name is mentioned online and finally plunge into social media sites for proper online reputation management.

Due to the multifarious possibilities of online reputation management, the extant studies have examined online reputation management in different perspectives. Wei, Yu, and Chen, (2017) found a gap in online reputation in the social e-commerce and discovered the factors that are responsible for online reputation formation in social commerce. Medeiros, (2017) focused on reputation management industry with legal undertone and try to bridge the gap between legal protection and the perceived harm and rebuff the idea of the online reputation management industry to retard the freedom of speech. In the battle for fairness in online review sentiment, Aureli, and Supino, (2017) probe into the reason why the hotel managers monitored online reviews and the study reveals rating, rankings and guest comments as the utmost triple elements of online reputation management. Ji, Li, North, and Liu, (2017) deviate from the norm of customer online reputation management and explore how Facebook engagement can help or hurt a company's reputation and concluded that the positive or negative of active stakeholders' through Facebook can predict the company's reputation score. Dijkmans, Kerkhof, and Beukeboom, (2015) linked social media with corporate reputation and find out if the online activities to engage consumers are beneficial to build corporate reputation and they discovered that social media use is associated with consumer's engagement. Since online reputation management is complex, Portmann, Meier, Cudré-Mauroux, and Pedrycz, (2015) came up with a fuzzy set framework to simplify online reputation management.

The different intensity of research focusing on the hot topics related to the union of mobile commerce and social media and rare statistical reputation in the developing country such as Nigeria actuate further investigation of mobile social commerce as an antecedent of online reputation management. The study employed sentiment analysis for mobile commerce Facebook followers' opinions, sentiments, evaluations, appraisals, attitudes, and emotions towards entities such as products and services (Bing, 2012). This paper is guided by a general 
objective to analyze the interwovenness of mobile commerce and social media with these specific objectives: (1) to state the importance of social media in online shopping, (2) to analyze online Facebook review sentiment and examine customer service (3) to showcase how to use review sentiment for online reputation management. Section one of the study introduced social media and online reputation management. Section two presents the theoretical framework. Section three described the methodology approach. Section four showcase the sentiment data analysis while section five, the concluding part discussed the result and gives managerial implication, limitation of the study and recommends future research.

\section{Sentiment Analysis Research}

Opinions are central to almost all human activities because they are key influencers of our behaviors (Bing, 2012). We want to know others' opinions whenever we need to make a decision, for example, individual consumers want to know the opinions of existing users of a product before purchasing it, and others' opinions about political or social issue or events. Organizations and businesses owners always want to find consumer or public opinions about their products and services, which in the time past, they must result in asking friends and family, conducted surveys, opinion polls, and focus groups. All these processes may no longer be necessary because of abundance of such information publicly available through the web about the products and services. Individuals and organizations are increasingly using the content in social media (for example, reviews, forum discussions, blogs, micro-blogs, Facebook, Twitter, comments, and postings in social network sites) for decision making due to its explosive growth on the Web. According to Bing, (2012), opinionated postings in social media have helped reshape businesses and sway public sentiments and emotions, which have profoundly impacted on social and political systems as such postings have also mobilized masses for political changes as it happened in some Arab countries in 2011. Bing stressed that it has thus become a necessity to collect and study opinions on the Web, though, opinionated documents not only exist on the Web (called external data), many organizations also have their internal data, e.g., customer feedback collected from emails and call centers or results from surveys conducted by the organizations. Opinions have also been categorized as two types, that is, regular opinions (Liu, 2006 and 2011) and comparative opinions (Jindal and Liu, 2006b). A regular opinion can be direct or indirect opinion which expresses a sentiment only on an entity or an aspect of the entity. A comparative opinion expresses a relation of similarities or differences between two or more entities and/or a preference of the opinion holder based on some shared aspects of the entities (Jindal and Liu, 2006a; Jindal and Liu, 2006b).

Sentiment analysis, also called opinion mining, is the field of study that analyzes people's opinions, sentiments, evaluations, appraisals, attitudes, and emotions towards entities such as products, services, organizations, individuals, issues, events, topics, and their attributes (Bing, 2012). The research on sentiments and opinions appeared earlier (Das and Chen, 2001; Morinaga et al., 2002; Pang, Lee and Vaithyanathan, 2002; Tong, 2001; Turney, 2002; Wiebe, 2000) as its applied on classifying online news text (Christopher, Armineh and Jin-Cheon, 2012), movie reviews or product reviews (Kennedy and Inkpen, 2005, 2006; Thet, Na, Khoo and Shakthikumar, 2009) as positive or negative or identifying positive and negative sentences, but many recent applications involve opinion mining in ways that require a more detailed analysis of the sentiment expressed in texts. Several studies have also been carried out on sentiment analysis on social media (Neri, Aliprandi, Capeci, Cuadros and By, 2012; Kowcika, 
Gupta, Sondhi, Shivhre, and Kumar, 2013) and specifically on twitter (Pak and Paroubek, 2010; Kouloumpis, Wilson and Moore, 2011; Agarwal, Xie, Vovsha, Rambow and Passonneau, 2011; Martinez-Camara, Martin-Valdivia, Urenalopez and Montejoraez, 2012; Hassan, Miriam, Yulan and Harith, 2013; Fornacciari, Mordonini and Tomaiuolo, 2015;) and very few on facebook (Ortigosa, Martín and Carro, 2014). Bing identified three levels at which sentiment analysis has been mainly investigated as follows:

Document level: This level classified whether a whole opinion document expresses a positive or negative sentiment (Pang, Lee and Vaithyanathan, 2002; Turney, 2002). In a product review, the system determines whether the review expresses an overall positive or negative opinion about the product. This task is commonly known as document-level sentiment classification. This level of analysis assumes that each document expresses opinions on a single entity or single product and not applicable to documents which compare multiple entities.

Sentence level: This level task goes to the sentences and determines whether each sentence expressed a positive, negative, or neutral opinion (no opinion).

Entity and Aspect level: This was earlier called feature-based opinion mining and summarization by Hu and Liu, (2004). Both the document level and the sentence level analyses do not discover what exactly people liked and did not like. Aspect level performs finer-grained analysis. Instead of looking at language constructs (documents, paragraphs, sentences, clauses or phrases), aspect level directly looks at the opinion itself. It is based on the idea that an opinion consists of a sentiment (positive or negative) and a target (of opinion).

\section{Theoretical Framework}

Appraisal theory claims that people evaluate the personal meaning of an exciting event or events before emotional responses are generated (Cherng and Timmy, 2015). The appraisal theory of emotion has been used to examine the relationships between appraisals, consumption emotions and post-consumption behaviors (Bougie et al., 2003; Nyer, 1997; Soscia, 2007). The form and emergence of emotions depend on cognitive appraisal process which are byproducts of cognitive appraisal process (Bagozzi et al., 1999; Lazarus and Lazarus, 1994).

Bloom (2011), said the theory of appraisal shift sentiments classification further and considers the assessment expression as a basic grammatical unit by which an opinion is expressed. Opinion are classified in previous studies mainly to their polarity as positive, negative or neutral besides which appraisal expressions covers additional attributes of opinions that extend the core description of the expressed opinion (Šimko and Korenek, 2014). The basic attributes attitude, which are engagement and graduation are complementary with polarity/orientation (Martin and White, 2005).

The identified attributes of appraisal theory are:

Attitude - Attitude is the essence of emotion the appraiser conveys about the product or services. It is about a talk on how it affects the appraisers feeling such as anger, fear, jealousy, excitement, hostility, satisfaction or appreciation. Emotions or attitudes that can be expressed in appraisal groups, such as: "It's such a wonderful day!". In more formal contexts such as news articles, expressions such as "This policy will not work" are considered appraisal groups conveying attitude.

Graduation - Graduation refers to the strength or force of emotion and attitude in each 
appraisal group. Adverbs such as "fairly" or "soulfully" indicate graduation. Words used to express attitude can also contain an indication of graduation, for example, "dislike" versus "detest".

Engagement - Sentiment can be expressed directly or indirectly or attributed to another source. Engagement is the way speakers or writers' express appraisal or engage in the argument. The engagement is monoglossic if the speaker/writer has directly expressed the appraisal, e.g. "The President has no idea what he is talking about". It is heteroglossic if the speaker/writer has either attributed to another source or has tried to use other methods to prove the point or make it more credible, for example, "Data from previous studies show there is little hope that his strategy will work" (Christopher, Khoo and Jin-Cheon, 2012).

Orientation - It recognizes if a term is positive or negative. Some studies refer to this attribute as polarity (Pandey and Iver 2009). In contrast, the polarity attribute represents the fact that a sentimental term can be unmarked or marked. That means that the term "orientation" can be influenced by an expression that negates the meaning of the phrase or a sentence. If a term contains such a negation (not, never), it is labelled as marked.

According to Simko and Korenek (2014), the main advantage of using the appraisal theory in sentiment classification is that it helps to look deeper inside the mind of authors who wrote texts and find out their real meaning using linguistic and psychological analysis of their texts.

Table 1. Extant Studies on Union of Mobile Commerce and Social Media

\begin{tabular}{|c|c|c|c|c|c|}
\hline Author(s) & Phenomenon & Setting & Theory & Methodology & Research finding \\
\hline $\begin{array}{l}\text { Demitrios E. } \\
\text { Pournarakis, } \\
\text { Dionisios N. } \\
\text { Sotiropoulos, } \\
\text { George M. } \\
\text { Giaglis }\end{array}$ & $\begin{array}{l}\text { A } \\
\text { computational } \\
\text { model for } \\
\text { mining } \\
\text { consumer } \\
\text { perceptions in } \\
\text { social media. }\end{array}$ & $\begin{array}{l}\text { Twitter } \\
\text { Online } \\
\text { Platform }\end{array}$ & $\begin{array}{l}\text { Computational } \\
\text { Model }\end{array}$ & Case Study & $\begin{array}{l}\text { The } \\
\text { computational } \\
\text { model applied in } \\
\text { this study } \\
\text { generate four key } \\
\text { insights: (a) } \\
\text { overall volume of } \\
\text { tweets and } \\
\text { prevailing topics } \\
\text { discussed, (b) } \\
\text { daily sentiment } \\
\text { towards the } \\
\text { brand, (c) optimal } \\
\text { clustering of } \\
\text { tweets in } \\
\text { semantically- } \\
\text { coherent clusters } \\
\text { under a distinct } \\
\text { topic, and (d) an } \\
\text { overall average } \\
\text { sentiment } \\
\text { assessment of } \\
\text { each topic per } \\
\text { day. }\end{array}$ \\
\hline
\end{tabular}




\begin{tabular}{|c|c|c|c|c|c|}
\hline $\begin{array}{l}\text { Eyad Makki } \\
\text { and Lin- } \\
\text { Ching Chang }\end{array}$ & $\begin{array}{l}\text { Understanding } \\
\text { the Effects of } \\
\text { Social Media } \\
\text { and Mobile } \\
\text { Usage on E- } \\
\text { Commerce: } \\
\text { An } \\
\text { Exploratory } \\
\text { Study in Saudi } \\
\text { Arabia. }\end{array}$ & Country & - & $\begin{array}{l}\text { Online Survey } \\
\text { (Qualitative } \\
\text { Approach) }\end{array}$ & $\begin{array}{l}\text { The authors } \\
\text { found that social } \\
\text { media and mobile } \\
\text { usage play } \\
\text { significant roles } \\
\text { on E-commerce } \\
\text { in Saudi Arabia. }\end{array}$ \\
\hline $\begin{array}{l}\text { Jun-Jie Hew, } \\
\text { Voon-Hsien } \\
\text { Lee, Keng- } \\
\text { Boon Ooi, } \\
\text { Binshan Lin }\end{array}$ & $\begin{array}{l}\text { Mobile social } \\
\text { commerce: } \\
\text { The booster } \\
\text { for brand } \\
\text { loyalty? }\end{array}$ & Continent & $\begin{array}{l}\text { Expectation } \\
\text { Confirmation } \\
\text { Model }\end{array}$ & $\begin{array}{l}\text { Self- } \\
\text { administered } \\
\text { questionnaire } \\
\text { survey } \\
\text { (Quantitative } \\
\text { Approach) }\end{array}$ & $\begin{array}{l}\text { The study } \\
\text { discovered that } \\
\text { both continuance } \\
\text { intention to } \\
\text { use mobile social } \\
\text { commerce and } \\
\text { satisfaction on } \\
\text { mobile social } \\
\text { commerce is } \\
\text { influencing brand } \\
\text { loyalty positively. }\end{array}$ \\
\hline $\begin{array}{l}\text { Wee-Kek } \\
\text { Tan, Hock- } \\
\text { Hai Teo, } \\
\text { Chuan-Hoo } \\
\text { Tan, and } \\
\text { Yang Yang }\end{array}$ & $\begin{array}{l}\text { The Social } \\
\text { Dimension of } \\
\text { Mobile } \\
\text { Commerce - } \\
\text { Engaging } \\
\text { Customers } \\
\text { Through } \\
\text { Group } \\
\text { Purchase }\end{array}$ & Global & $\begin{array}{l}\text { Using the } \\
\text { engagement } \\
\text { cycle as the } \\
\text { theoretical } \\
\text { lens. }\end{array}$ & $\begin{array}{l}\text { Methods of } \\
\text { the group } \\
\text { purchase } \\
\text { social process } \\
\text { and } \\
\text { instantiation } \\
\text { of the mobile } \\
\text { commerce } \\
\text { application. }\end{array}$ & $\begin{array}{l}\text { The authors } \\
\text { addressed the } \\
\text { three design } \\
\text { features that are } \\
\text { currently not } \\
\text { found in both e- } \\
\text { commerce } \\
\text { focus and social } \\
\text { media focus } \\
\text { implementation } \\
\text { approaches of } \\
\text { social commerce. } \\
\text { They are } \\
\text { community } \\
\text { support, } \\
\text { relationship } \\
\text { maintenance and } \\
\text { group purchase. }\end{array}$ \\
\hline $\begin{array}{l}\text { Jean-Eric } \\
\text { Pelet, } \\
\text { Panagiota } \\
\text { Papadopoulou }\end{array}$ & $\begin{array}{l}\text { Social media } \\
\text { and m- } \\
\text { commerce }\end{array}$ & Campus & - & $\begin{array}{l}\text { exploratory } \\
\text { (Qualitative } \\
\text { approach) }\end{array}$ & $\begin{array}{l}\text { The authors } \\
\text { analysis shows } \\
\text { that there is a } \\
\text { growing use of } \\
\text { social media on } \\
\text { mobiles and a } \\
\text { positive attitude }\end{array}$ \\
\hline
\end{tabular}




\begin{tabular}{|c|c|c|c|c|c|}
\hline & & & & & $\begin{array}{l}\text { and behaviour } \\
\text { towards } \\
\text { m-commerce, } \\
\text { especially when it } \\
\text { is combined with } \\
\text { social media. The } \\
\text { most important } \\
\text { factors that affect } \\
\text { m-commerce and } \\
\text { social media } \\
\text { adoption and use } \\
\text { can be } \\
\text { summarised to } \\
\text { trust, reputation } \\
\text { from others that } \\
\text { use them, speed, } \\
\text { ease-of-use and } \\
\text { security. }\end{array}$ \\
\hline $\begin{array}{l}\text { Andreas M. } \\
\text { Kaplan, } \\
\text { Michael } \\
\text { Haenlein }\end{array}$ & $\begin{array}{l}\text { Users of the } \\
\text { world, unite! } \\
\text { The } \\
\text { challenges } \\
\text { and } \\
\text { opportunities } \\
\text { of Social } \\
\text { Media }\end{array}$ & Global & $\begin{array}{l}\text { Social } \\
\text { presence, } \\
\text { media } \\
\text { richness and } \\
\text { social } \\
\text { processes }\end{array}$ & $\begin{array}{l}\text { Conceptual } \\
\text { (Classification } \\
\text { approach). }\end{array}$ & $\begin{array}{l}\text { The authors } \\
\text { provide a } \\
\text { classification of } \\
\text { Social Media } \\
\text { which groups } \\
\text { applications } \\
\text { currently } \\
\text { subsumed under } \\
\text { the generalized } \\
\text { term into } \\
\text { more specific } \\
\text { categories by } \\
\text { characteristic: } \\
\text { collaborative } \\
\text { projects, blogs, } \\
\text { content } \\
\text { communities, } \\
\text { social networking } \\
\text { sites, virtual } \\
\text { game worlds, and } \\
\text { virtual social } \\
\text { worlds and also } \\
\text { present } 10 \text { pieces } \\
\text { of advice for } \\
\text { companies which } \\
\text { decide to utilize } \\
\text { Social Media. }\end{array}$ \\
\hline
\end{tabular}


Figure 1 below evince the model of the study which shows the interconnectedness among various variables depicting the union of Mobile Commerce and Social Media.

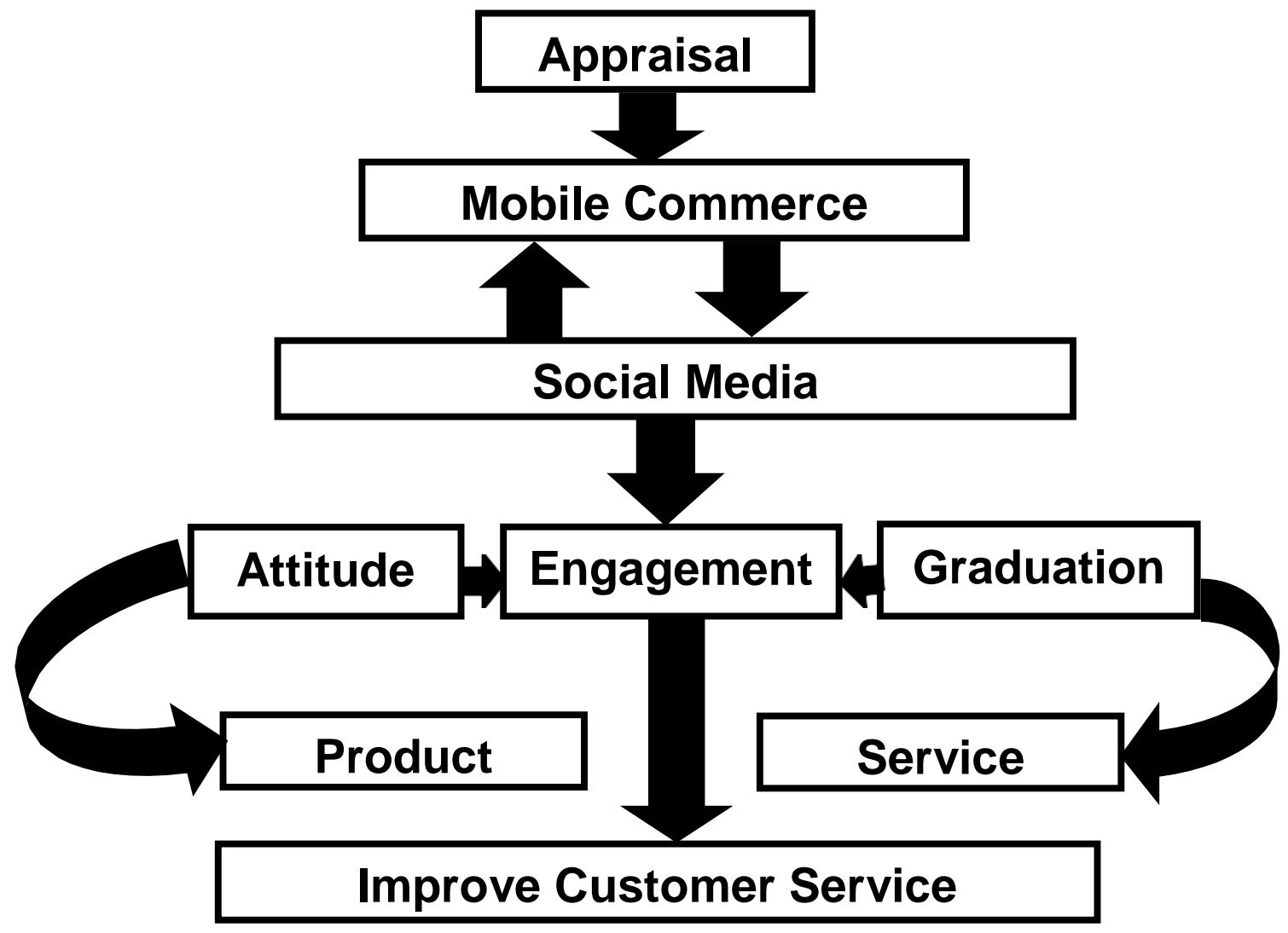

Figure 1: Social Commerce Model

\section{Methodology}

The growth of technology most especially in social media is utilizing a different kind of research methodology due to its vastness. This paper seeks to use a hybrid approach that combines different methodology and data analysis techniques such as entity and aspect-level sentiment, manual techniques, data mining, text mining and netnography to overcome some of the problems that existing researchers had identified concerning sentiment analysis of social media in their studies. Some of the authors have identified the problem of using slangs, disjointed words, incomplete phrase or sentence and buzz words that lack proper understanding and meaning. Kozinets (2010, p.1) defined netnography as "a form of ethnographic research, adopting the participant-observational approach and taking online interactions as its fieldwork". Netnography preponderates tourism research stream Wu and Pearce (2014), but Kozinets (2015) recommends Netnography methodology to researchers that work with social media and other online platforms.

The study followed five-stage outlines mapped out by Kozinets (2010) to extract data from electronic commerce Facebook online community as a participant-observer. We planned the data collection, the data extraction, coding on getting insight from the data. One of the authors represented himself on the e-commerce Facebook online community as an observer, and we 
extracted the data with NCapture, a browser plug-in that allows us to capture the data of ecommerce product and service reviewers. We opted for NCapture among others because of its file transfer compatibility with NVivo 11 Plus that we adopted for data coding. For this study, we used NVivo 11 Plus for e-commerce merchants' classifications and aspect-level sentiment analysis with observance of relevant ethical issues. We also used NVivo 11 Plus for data, text mining and complement it with LikeAlyzer, an online Facebook analysis tool to

calculate the Facebook online community engagement rate based on the following formula: $\frac{\mathrm{p}}{\mathrm{l}}$ =E. P: represent People Talk About This (PTAT - Facebook Followers), L: depicts Likes (Facebook Fans) while E: equals Engagement Rate (Tables 1, 2 and 3 illustrate the engagement rate of 10 General Ecommerce Merchant Retailers, 15 Specialty Retailers and 8 Agency Retailers respectively).

\section{Sentiment Data Analysis}

The emergence of the social media has turned things around in mobile commerce. In social media, retailers can only measure their Return on Investment (ROI) through advertisement in form of sales but to appraise the sold-out products and services rendered to the customers, is a bit challenging. Through online reviews and posts through social media like Facebook, it is easy for online community members to learn from one another, express their experience, opinion and synchronise cultures. We adopted five steps process posited for sentiment analysis from the work of Nikumbh, Nikumbh and Gaikwad, (2016). We skipped data collection and text preparation postulated by Nikumbh et al. (2016) because we had earlier used Netnography approach, but we used NVivo with manual techniques for sentiment detection, sentiment classification and output presentation. We exported data extracted with NCapture to the NVivo which consists 15,790 General Merchants Retailers reviews, 1,559 Specialty Retailers reviews and only 256 Agency Retailers reviews. All together for 33 electronic merchants in Nigeria, we had 17,605 Facebook reviews. We used the word query to analyse the most frequent one thousand words. The result gave us a clue to the keywords that are necessary for coding to discover emerging themes from the data. We also performed word frequency clustering analysis for the General Merchant Retailers, Specialty Retailers and Agency Retailers (See figure 2 for thematic analysis in details). 


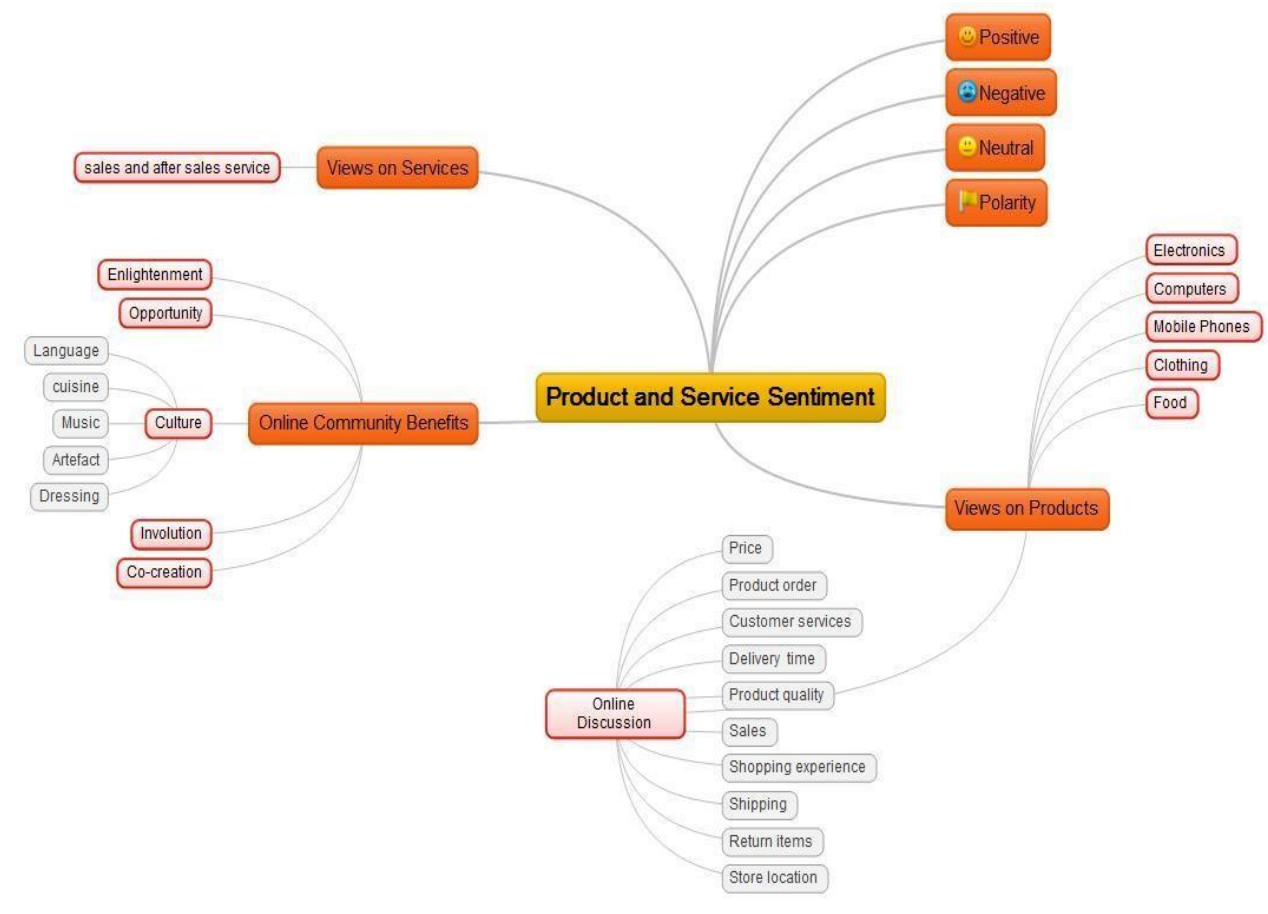

Figure 2: NVivo 11 Plus Thematic Analysis

We performed Jaccard similarity coefficient analysis between positive and negative review of Facebook online community reviews for e-commerce products and services. We performed Jaccard statistic test with NVivo 11 Plus to compare the similarity and diversity of positive and negative online community sample. If the sets data result would be $100 \%$ similar, it means the closer to $100 \%$ signify the intensity of the similarity, and in comparison, $80 \%$ will be more similar than 70\%. NVivo generates Jaccard's coefficient result of 0.038961 based on 7235 positive and 1783 negative references. We multiplied the result by 100 , and it gives us $4 \%$. The word similarity of positive and negative reviews is $4 \%$. To get the dissimilarity of the positive and negative review, we subtract the Jaccard index from 100\% (100-4 = 96\%). The Jaccard distance between the positive and negative reviews is $96 \%$.

\subsection{Facebook Online Community Engagement Rate}

The tables below show the mobile commerce engagement rate on Facebook online community in Nigeria. 


\begin{tabular}{llllll}
\hline No. & GMR & Likes & PTAT & ER & Like Rank \\
\hline 1. & GMR1 & $1,192,581$ & 10,191 & $0.85 \%$ & 77 \\
2. & GMR2 & $1,521,848$ & 3,538 & $0.23 \%$ & 64 \\
3. & GMR3 & $6,841,120$ & 31,743 & $0.46 \%$ & 74 \\
4. & GMR4 & 16,975 & 360 & $2.12 \%$ & 61 \\
5 & GMR5 & 840 & 675 & $80.36 \%$ & 82 \\
6 & GMR6 & 27,199 & 12 & $0.04 \%$ & 59 \\
7 & GMR7 & 262,786 & 33,823 & $12.87 \%$ & 86 \\
8 & GMR8 & 38,078 & 755 & $1.98 \%$ & 53 \\
\hline
\end{tabular}

Table 1: General Merchant Retailer

\begin{tabular}{llllll}
\hline No. & SR & Likes & PTAT & ER & Like Rank \\
\hline 1. & SR1 & 496 & 1 & $0.2 \%$ & 15 \\
2. & SR2 & 68,206 & 209 & $0.31 \%$ & 50 \\
3. & SR3 & 7,336 & 888 & $12.1 \%$ & 77 \\
4. & SR4 & 70,053 & 176 & $0.25 \%$ & 39 \\
5. & SR5 & 54,510 & 22 & $0.04 \%$ & 38 \\
6. & SR6 & 2,427 & 0 & $0 \%$ & 21 \\
7. & SR7 & 308,02 & 762 & $0.25 \%$ & 53 \\
8. & SR8 & 4 & 2 & $0.08 \%$ & 12 \\
9. & SR9 & 2,403 & 5 & $0.3 \%$ & 49 \\
10. & SR10 & 2,324 & 96 & $0.26 \%$ & 50 \\
11. & SR11 & 37,188 & 488 & $0.17 \%$ & 56 \\
12. & SR12 & 284,40 & 2 & $0.11 \%$ & 17 \\
13. & SR13 & 8 & 6 & $0.06 \%$ & 27 \\
14. & SR14 & 1,778 & 29 & $0.05 \%$ & 35 \\
15. & SR15 & 9,513 & 5 & $0.04 \%$ & 39 \\
\hline
\end{tabular}

Table 2: Specialty Retailer

\begin{tabular}{llclll}
\hline No. & Page (Status) & Likes & PTAT & ER & Like Rank \\
\hline 1. & RA1 & 56,629 & 6 & $0.01 \%$ & 25 \\
2. & RA2 & 62,445 & 1,337 & $2.14 \%$ & 39 \\
3. & RA3 & 23,738 & 6 & $0.03 \%$ & 49 \\
4. & RA4 & 189,58 & 4,120 & $2.17 \%$ & 73 \\
5. & RA5 & 0 & 21 & $0.37 \%$ & 42 \\
6. & RA6 & 5,650 & 120,228 & $17.77 \%$ & 80 \\
7. & RA7 & 676,47 & 268 & $0.15 \%$ & 46 \\
8. & RA8 & 8 & 890 & $7.89 \%$ & 79 \\
\hline
\end{tabular}

Table 3: Retail Agency

As shown in the tables 1, 2 and 3 above, the Engagement Rate is calculated by taking the total PTAT (people talking about this) and divide by the total number of likes. Surveys show that to have success on Facebook, an engagement rate greater than $7 \%$ should be met as revealed by Facebook LikeAlyzer tool. In the GMR categorization, it shows that only two of the mobile commerce successfully engaged their customers with $80.36 \%$ and $12.87 \%$ respectively. All the specialty retailers sampled shows very low engagement with their clients while two of the retail agencies sampled indicated that they recorded success in engaging their customers at $17.77 \%$ and $7.89 \%$. This result reveals that generally, most of the Merchants and Vendors do 
not actually engage their customers. It is very important to note that it is not sufficient to only have as many likes as possible whereas having a very low PTAT, this yields a very low engagement rate as seen for example in Shoprite, Jumia and Konga. Again, recording a high or low PTAT and a corresponding number of likes will yield a very high engagement rate as evidenced in Katadeals, Payporte and Jiji. It is not enough to have millions of likes on the Facebook platforms of mobile commerce while PTAT is very low as it is crucial for a successful engagement rate with customers.

Our results, based on sentiments detection from the reviews on the Ecommerce merchant social media platform (Facebook) are classified under four headings. These are: views on Products and Services, Online Discussion, Merchant's Response and Online Community Benefits. These classifications identified the attributes of appraisal which include attitude, graduation, engagement and polarity as all these constructs are interlinking in the expressed opinions of consumers on products or services.

\subsection{Product and Service Sentiment}

The analysis starts by investigating polarity, which is useful for determining the overall sentiment orientation or bias of a document or person towards an object or services. Consumers shared their views on products such as electronics, computers, mobile phones, clothing and food items. We extracted the reviews of product and services from the Facebook page of mobile commerce platforms. The excerpts below depict the mind of the reviewers:

Positive: I love GMR (FS, Male, Lagos, January 16. 2017)

I like RA stores (UAO, Female, Owerri, January 26, 2017)

Negative: GMR is selling products that are of low standard, inferior and low in quality because I bought a 32-inch Sharp TV and after two weeks the TV couldn't power on. (FP, Male, Lagos, January 4, 2017).

Neutral: ...I have never had any issues with GMR... (AA, Male, Lagos, January 4, 2017). People have been talking about GMR but I never patronize them (IBF, Male, Abeokuta, November 24, 2016).

Polarity: The delivery is awesome but, 800 naira is too much within Lagos, I ordered for 6 different items, and they charge me 800 naira for each, which is very bad (AS, Male, Lagos, November 20, 2016).

I enjoyed the Lenovo tab I bought from them just that it doesn't have flash so painful (BIR, Female, Ilorin, November 15, 2015).

The above quotes from the customers of mobile shoppers' shows their Polarity which are positive, negative and neutral.

\subsection{Online Discussion}

The most discussed topic that generated contributions from consumers on the e- commerce platforms as identified are price, product order, customer services, delivery time, product quality, shopping experience, shipping, return items, store location. This is evidenced in figure 2 above. The excerpts below express the mind of the reviewers:

Price: ...how can your price of shipping be more than the goods or items being Bought...If you keep going like this, it will get to a stage where no one will buy anything from GMR (NI, Female, Kano, September 8, 2016).

Product Order: Very poor. You place an order and never get a response. 
If a large company like Amazon with millions of daily orders can easily manage them, why can't... (BA, Male, Lagos, January 9, 2016).

Customer Services: The attitude of your rep AO is appalling. He is rude, arrogant and treat customers call with disdain. Please I need my order-xxxxxxxxx delivered tomorrow unfailingly (AMA, Male, Lagos, December 6, 2016).

Delivery Time: Customer care was wonderful. GMR especially could work on their delivery time too (JD, Male, Port Harcourt, July 15, 2016).

Product Quality: ...GMR selling products that are of low standard, inferior and low in quality. (FP, Male, Lagos, January 4, 2017).

Shopping Experience: ...I have a very terrible experience with SR in Abuja. If they offer you warranty or screen insurance, beware and run for your pocket (OO, Male, Abuja, November 1, 2016),

Shipping: GMR started well. I lost confidence in their products after they shipped me fake LG microwave and Havell toaster...(SN, Male, Nasarawa, November 13, 2015).

Return Items: I bought two shorts from RA for my baby at their store in Akure but was too small for him. Please can I return it for exchange (OAI, Female, Ekiti, December 27,2015).

Store Location: I haven't Patronize RA so I don't know what to say about them (JM, Female, Lagos, May 12, 2016).

The expression as seen in price shows the engagement aspect of appraisal with the statement being attributed to another source which shows heteroglossic engagement. In product order, the statement "very poor" shows negative polarity as the next sentence is attitudinal, and further statement expressed heteroglossic engagement. Consumer service review depicts attitude as well as negative like product quality review. For delivery time, the reviewer express graduation with the word "wonderful" used and the review for shopping experience shows negativity and heteroglossic engagement aspect of appraisal. Under shipping, the statement is categorized as polarity reviews made under the return items, and store location is neutral.

\subsection{Online Community Benefits}

The authors deduced certain advantages for the mobile shoppers as evidenced from their Facebook page reviews under the headings of enlightenment, opportunity, involution and cocreation.

Enlightenment: How To Make A Teddy Bear Out Of A Towel (RA, January 30, 2017).

Lovely. I will try to make one for my grandchildren. Practice makes perfect (CO, Female, Lagos, January 31, 2017).

Opportunity: Business opportunity!

...We are currently Leading an Expansion of a global fuel company and we are competing against the Trillions in Revenue ... (OD, Male, Lagos, May 29, 2014).

Involution: DO NOT SHOP ON GMR!! Product Quality always totally different from 
description their coupon doesn't work either they still charge the same amount even after using the coupon...crap!!! Don't do it please! (AA, Male, Lagos, January 4, 2017).

Culture: This include language, cuisine, music, artefact and dressing. The cultural display shows the interplay of various culture represented on the platform due to ethnic diversity of Nigerian states.

Co-creation: To maximise customers experience, SR should incorporate a 'trade-in' program. I have a good idea on how this can double the current turnover of SR business. Reach me via 080XXXXXXXX or xxxx@aol.com in case the business is interested in this idea (IA, Male, Iwo, July 13, 2014).

Enlightenment as a benefit brings about passing knowledge about something to others. This is shown in the statements made by the reviewers under enlightenment teaching themselves how to do new things. Customers advertises, exchange ideas and present business opportunities for other customers alike.

\subsection{Merchant's Response}

The merchant response is very important for whatever brand to communicate, engage the customers or consumers and redeem the image or solve issues relating to patronage and many more. Some of the excerpts below are from merchant responses to comments on their products and services.

...So sorry for this experience. Sadly, the item delivered is the item ordered. Since the seal has been broken, we'll be unable to retrieve the item. An agent has been assigned to contact you regarding this. Thank you (GMR Representative, December 21, 2016).

We're delighted to receive your feedback and are super glad that you enjoyed our service. (GMR Representative, December 30, 2016).

Thank you for your kind words VO, quite appreciated. Please spread the word... And we welcome referrals... (SR Representative, April 2, 2015).

The first response given above represent the attitude and the information passed as evident in the merchant comment reveals that the terms and condition of the agency is not known by the consumers as alluded to in the comment. The other responses received encouraging feedbacks about their product and services and they appreciated them. Going by the reviews generally, the rate of reply of the merchant to the reviewers is slow as there are complaints about response rate. It seems there is no personnel designated to answer the queries of customers.

\section{Conclusion and Implication}

Despite the prevalence of e-commerce, mobile commerce and social media as an interwoven study in diver disciplines (Huang and Benyoucef 2015), it is noted that few scholars in the field of electronic marketing have fully explored the connectedness of mobile commerce and social media for customers' service improvement. This study applies the hybrid technique to sort out social commerce customers' reviews, appraise the quality of the extracted data and identify the opinion that transpired between online retailing merchants and online customers. The unicity of this study lies in the accessibility of large dataset of online multiculturalism douse with emotion. Although this study is an overture of social commerce in the context of 
developing countries such as Nigeria, the study gain insight into the sentiment of online shopping. Due to this development, it is viewed that this study will set a pace for online shopping customer engagement through social media in electronic marketing. It makes this study one of the foremost in Nigeria. Our study contributes to the literature of electronic marketing in several ways. This study demonstrated the importance of social media in ecommerce in a new way by identifying the benefits of online community reviews and exhibited reviewers' emotions. Though our findings were based on Facebook data generated from 2014 to 2017, the result reflects how online shopping experiences ensued emotion in Facebook Commerce reviews. The study reveals the intensity of positive, negative, neutral and polarity sentiments. This study furthermore emphasized the explanatory power of theory for the union of mobile commerce and social media. The appraisal theory used for the pairing of mobile commerce and social media explain how attitude and graduation connect engagement in the context of products and services review. The equilibrium of mobile commerce and Facebook social media stands to improve customer service.

\section{Implications for Online Shopping Merchants and Vendors}

The study offers some managerial implications as it advocates the significance of social media in mobile commerce to the electronic marketing practitioner's due to its vastness. Many online consumers have turned Facebook into their second home, and it will be easy for the mobile commerce merchants to reach them for feedback in real-time. The study also emphasizes the importance of Facebook followers and clarify the differences between the Facebook likes and PTAT as the determinant of customer's online engagement. The engagement rate is one of the useful metrics for Merchants that uses Facebook online reviews. In addition, the application of the result of this study will guide the online merchants and vendors to establish an online bi-directional communication with clarity of expression. It will also facilitate an increasing engagement rates as settlement of disparity foster's a mutual understanding and a deeper relationship. It gives direction to an enhancement customer's service and insight for viable marketing strategy. Importantly, the framework proposed in this study will serve as a foundation and precedent for an effective online reputation management in three ways. First, it will be useful for negative comment management. Second, it will help to build an acceptable reputation and re-build a dent reputation and lastly, it will help merchants to position their brand and to establish a strong brand presence that can compete in a fierce market.

\section{Study Limitation}

This study is not without limitations, and its explanation should be treading carefully. It is a common argument that social media data validity is not a clean-cut (He et al. 2014, Panger 2016) but (Rife et al. 2016) recommends heterogeneous Facebook users and generalized result as a standard for online data validity. In their study, they testify to the viability of Facebook data over traditional samples. Demographic data is hard to extract, but we limit the quotes to the reviewers that make their name, sex, domicile available on their Facebook page. There were more positive reviews (80\%) than the negative (20\%), and the neutral and polarity were scanty. Another limitation was that the sample represents general merchants retailing, specialty retailing and agency retailing and only 33 of the mobile commerce retailers were available for this study.

\section{Future Research Direction}

Future studies should endeavor to examine online reviews of social media such as Twitter, 
Instagram, Google+ and Pinterest regarding mobile commerce as a comparative study. Furthermore, the future researcher should come up with the drivers and inhibitors of online reputation management and compare the down-to-earth technological tools for efficient online reputation management in the context of developing nations.

\section{References}

Agarwal, A., Xie, B., Vovsha, I., Rambow, O. and Passonneau. R. (2011), 'Sentiment analysis of Twitter data', Procs of the Workshop on Languages in Social Media (LSM '11), pp. 30-38.

Aureli, S., \& Supino, E. (2017), 'Online Reputation Monitoring: An Exploratory Study on Italian Hotel Managers' Practices', International Journal of Hospitality \& Tourism Administration, Vol. 18, No.1, pp. 84-109.

Bagozzi, R.P., Gopinath, M. and Nyer, P.U. (1999), 'The role of emotions in marketing', Journal of the Academy of Marketing Science, Vol. 27 No. 2, pp. 184-206.

Bing, L. (2012), 'Sentiment Analysis and Opinion Mining', Morgan \& Claypool Publishers.

Bloom, K. (2011). Sentiment analysis based on appraisal theory and functional local grammars. Dissertation, Illinois Institute of Technology.

Bougie, R., Pieters, R. and Zeelenberg, M. (2003), 'Angry customers don't come back, they get back: the experience and behavioral implications of anger and dissatisfaction in services', Journal of the Academy of Marketing Science, Vol. 31, No. 4, pp. 377-393.

Cherng G. Ding \& Timmy H. Tseng, (2015), 'On the relationships among brand experience, hedonic emotions, and brand equity', European Journal of Marketing, Vol. 49, No. 7/8 pp. 994 - 1015. http://dx.doi.org/10.1108/EJM-04-2013-0200.

Christopher Soo-Guan Khoo, Armineh Nourbakhsh \& Jin-Cheon Na, (2012), 'Sentiment analysis of online news text: a case study of appraisal theory', Online Information Review, Vol. 36, No. 6 pp. 858 - 878, http://dx.doi.org/10.1108/14684521211287936.

Das, Sanjiv and Mike Chen, (2001), 'Yahoo! for Amazon: Extracting market sentiment from stock message boards', in Proceedings of APFA-2001.

Dijkmans, C., Kerkhof, P., \& Beukeboom, C. J. (2015), 'A stage to engage: Social media use and corporate reputation' Tourism Management, Vol. 47, pp. 58-67.

Fornacciari, P., Mordonini, M and Tomaiuolo, M. (2015), 'A Case-Study for Sentiment Analysis on Twitter' In Proc. of the 16th Workshop "From Object to Agents" (WOA15) June 17-19, Naples, Italy.

Hassan, S., Miriam, F., Yulan, H. and Harith, A. (2013), 'Evaluation datasets for Twitter sentiment analysis: a survey and a new dataset, the STS-Gold', Proc. of ESSEM 2013, Turin, Italy.

He, Q., Glas, C. A., Kosinski, M., Stillwell, D. J., \& Veldkamp, B. P. (2014), 'Predicting selfmonitoring skills using textual posts on Facebook', Computers in human behavior, Vol. 33 , pp. 69-78.

Hoffman, T. (2008), 'Online reputation management is hot—but is it ethical', Computerworld, February, pp. 1-4.

$\mathrm{Hu}$, Minqing and Bing Liu. (2004), 'Mining and summarizing customer reviews', In Proceedings of ACM SIGKDD International Conference on Knowledge Discovery and Data Mining (KDD-2004).

Huang Z. \& Benyoucef, M. (2015), 'User preferences of social features on social commerce websites: An empirical study', Technological Forecasting \& Social Change, Vol. 95, pp.57-72. 
Internet World Stats (2017), http://www.internetworldstats.com/stats1.htm, [online], Accessed 12.02.2017.

Ivester, M. (2011). 'Lol--Omg!: What Every Student Needs to Know about Online Reputation Management', Digital Citizenship, and Cyberbullying. Serra Knight Pub.

Ji, Y. G., Li, C., North, M., \& Liu, J. (2017), 'Staking reputation on stakeholders: How does stakeholders' Facebook engagement help or ruin a company's reputation?', Public Relations Review, Vol. 43, No.1, 201-210.

Jindal, Nitin and Bing Liu. (2006a), 'Identifying comparative sentences in text documents' in Proceedings of ACM SIGIR Conf. on Research and Development in Information Retrieval (SIGIR-2006).

Jindal, Nitin and Bing Liu. (2006b), 'Mining comparative sentences and relations' In Proceedings of National Conf. on Artificial Intelligence (AAAI-2006).

Kennedy, A., \& Inkpen, D. (2005), 'Sentiment classification of movie and product reviews using contextual valence shifters', In Proceedings of the Workshop on the Analysis of Informal and Formal Information Exchange during Negotiations, Ottawa, Ontario, Canada.

Kennedy, A., \& Inkpen, D. (2006), 'Sentiment classification of movie reviews using contextual valence shifters, Computational Intelligence, Vol. 22, No.2, pp.110-125.

Kouloumpis, E., Wilson, T., \& Moore, J. (2011), 'Twitter sentiment analysis: The Good the Bad and the OMG!', In Proceedings of the 5th International AAAI Conference on Weblogs and Social Media.

Kowcika,A, Gupta, A., Sondhi, K., Shivhre, N. and Kumar, R. (2013), 'Sentiment Analysis for Social Media', Int. J. of Advanced Research in Computer Science and Software Engineering, Vol. 3, No.7.

Kozinets, R. V. (2010), 'Netnography: Doing ethnographic research online', Sage publications.

Kozinets, R. V. (2015), 'Netnography', Wiley Online Library.

Lazarus, R.S. and Lazarus, B.N. (1994), Passion and Reason: Making Sense of Our Emotions, Oxford University Press, New York, NY.

Liu, Bing. Web Data Mining: Exploring Hyperlinks, Contents, and Usage Data, (2006) and (2011)', Springer.

Madden, M. (2012), 'Privacy management on social media sites', Pew Internet Report, pp.120.

Martin, J.R., \& White, P.R.R. (2005), The Language of Evaluation: Appraisal in English, Palgrave Macmillan, London.

Martinez-Camara, E., Martin-Valdivia, M. T., Urenalopez, L. A., \& Montejoraez, A. R. (2012), 'Sentiment analysis in Twitter', Natural Language Engineering, pp. 1-28.

Medeiros, B. (2017), 'The reputation-management industry and the prospects for a "right to be forgotten" in the US', First Amendment Studies, Vol. 51, No.1, pp.14-29.

Morinaga, Satoshi, Kenji Yamanishi, Kenji Tateishi, and Toshikazu Fukushima (2002), 'Mining product reputations on the web', In Proceedings of ACM SIGKDD International Conference on Knowledge Discovery and Data Mining (KDD-2002).

Neri, F., Aliprandi, C., Capeci, F., Cuadros. M., and By, T. (2012), 'Sentiment Analysis on Social Media', Proceedings of the 2012 Int. Conf. on Advances in Social Networks Analysis and Mining (ASONAM '12), IEEE Computer Society, pp: 919-926, 2012.

Nikumbh, U., Nikumbh, P. \& Gaikwad, B. (2016), 'Sentiment Analysis : On Product Review', International Journal for Research in Engineering Application \& Management (IJREAM), Vol.2, No.2. 
Nyer, P.U. (1997), 'A study of the relationships between cognitive appraisals and consumption emotions', Journal of the Academy of Marketing Science, Vol. 25 No. 4, pp. 296-304.

Ortigosa, A., Martín, J. M. \& Carro, R. M. (2014), 'Sentiment analysis in Facebook and its application to e-learning', Computers in Human Behavior, Vol. 31, pp. 527-541.

Pak, A and Paroubek, P. (2010), 'Twitter as a corpus for sentiment analysis and opinion mining', In Proc. of the 7th conf. on International Language Resources and Evaluation (LREC'10). Valletta, Malta, May 2010.

Pandey. V., Iver, C. (2009), 'Sentiment analysis of microblogs', [online], http://www.stanford.edu/class/cs229/proj2009/PandeyIyer.pdf. Accessed 12.02.2017.

Pang, Bo, Lillian Lee, and Shivakumar Vaithyanathan (2002), 'Thumbs up: sentiment classification using machine learning techniques', In Proceedings of Conference on Empirical Methods in Natural Language Processing (EMNLP-2002).

Panger, G. 2016, 'Reassessing the Facebook experiment: critical thinking about the validity of Big Data research', Information, Communication \& Society, Vol.19, No.8, pp.11081126.

Portmann, E., Meier, A., Cudré-Mauroux, P., \& Pedrycz, W. (2015), 'FORA-A fuzzy set based framework for online reputation management', Fuzzy sets and systems, Vol. 269, pp. 90-114.

Rife, S. C., Cate, K. L., Kosinski, M., \& Stillwell, D. (2016), 'Participant recruitment and data collection through Facebook: The role of personality factors', International Journal of Social Research Methodology, Vol. 19, No.1, pp.69-83.

Šimko M. \& Korenek, P. (2014), 'Sentiment analysis on microblog utilizing appraisal theory', World Wide Web, Vol. 17, pp. 847-867.

Soscia, I. (2007), 'Gratitude, delight, or guilt: the role of emotions in predicting post consumption behaviors', Psychology and Marketing, Vol. 24, No.10, pp.871-894.

Thet, T. T., Na, J. C., Khoo, C. S. G., Shakthikumar, S. (2009), 'Sentiment analysis of movie reviews on discussion boards using a linguistic approach', In: Proc. of the 1st Int. CIKM workshop on Topic-sentiment analysis for mass opinion, TSA '09, ACM, pp. 81-84.

Tong, R M. (2001), 'An operational system for detecting and tracking opinions in on-line discussion', In Proceedings of SIGIR Workshop on Operational Text Classification.

Turney, P D. (2002), 'Thumbs up or thumbs down?: semantic orientation applied to unsupervised classification of reviews', In Proceedings of Annual Meeting of the Association for Computational Linguistics (ACL-2002).

Vconnect, (2017), 'Online Reputation Management in Lagos', [online], https://www.vconnect.com/lagos/list-of-online-reputation-management-vendorssearch_s793?page. Accessed on: 18.09.2017.

Wei, C., Yu, Z. J., \& Chen, X. N. (2017), 'Research on social e-commerce reputation formation and state-introduced model'. Kybernetes, Vol. 46, No. 6, pp.1021-1038.

Wiebe, Janyce. (2000). Learning subjective adjectives from corpora. In Proceedings of National Conf. on Artificial Intelligence, (AAAI-2000).

Wu, Mao-Ying, and Pearce, Philip L. (2014), 'Chinese recreational vehicle users in Australia: a netnographic study of tourist motivation’ Tourism Management, Vol. 43. pp.22-35. 